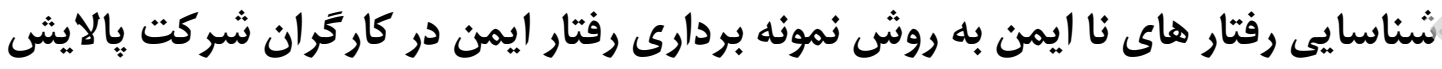

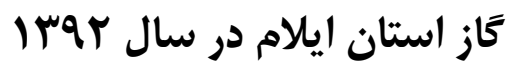

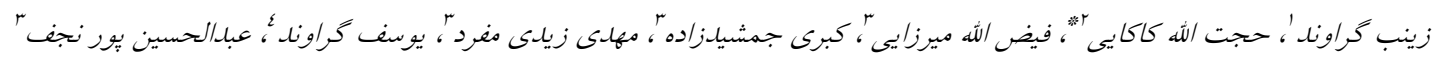

() كميته تحقيقات دانشبجويى، دانشكاه علوم يزشكى إيلام، إيلام، إيرلن

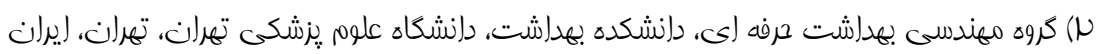

مر كروه مهندسى بهد(شت حرفه إى، دلنشكده بهداشت، دانشكاه علوم يزشكى إيلام، إيلام، إيرلن

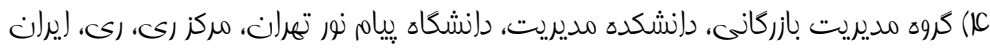

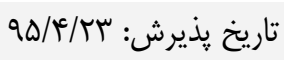

تاريخ دريافت:

\section{جُكيده}

مقدمه: يالايشحاه كاز يكى از صنايع استراتزيك در كشور است و وقوع حوادث در آن مى تواند باعث ايجاد خسارات جبران نايذيرى شود

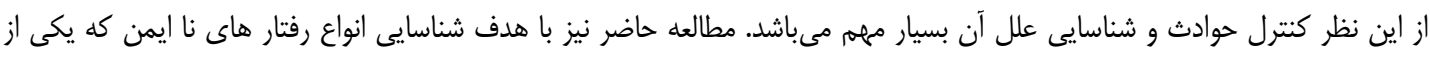

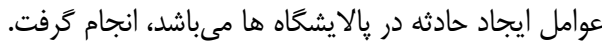

مواد و روث ها: دراين يثوهش توصيفى - مقطعى اعمال نا ايمن كاركران با استفاده از تكنيك نمونه بردارى از رفتار ايمن و با بهره

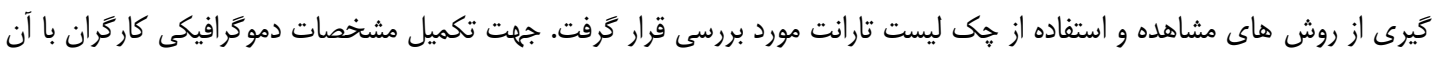

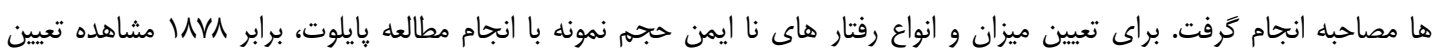

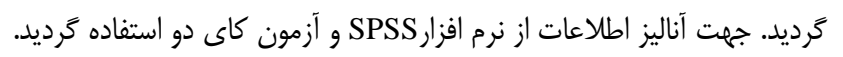

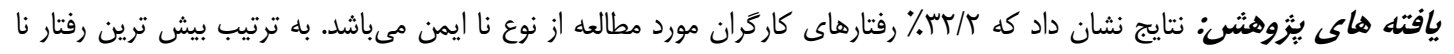

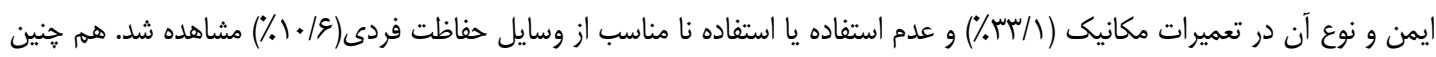

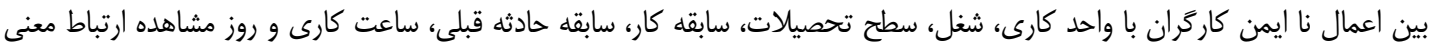

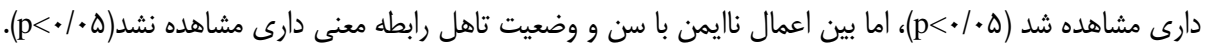

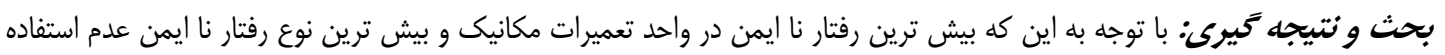

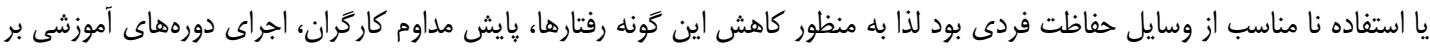

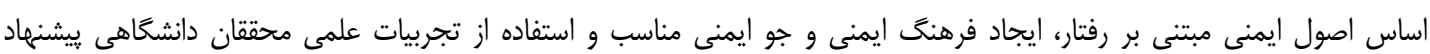
مى گردد.

$$
\text { وازه هاى كليدى: رفتار نا ايمن، نمونه بردارى رفتار، يالايش كاز، ايلام }
$$

* نو يسنده مسئول : كروه مهندسى بهداشت حمفه اكى، دانشكده بهداشت، دانشكاه علوم پزشكى تهرلن، تهرلن، ليران

Email: hojatkakaei@gmail.com

Copyright (c) 2017 Journal of Ilam University of Medical Science. This is an open-access article distributed under the terms of the Creative Commons Attribution international 4.0 International License (https://creativecommons.org/licenses/by-nc/4.0/) which permits copy and redistribute the material, in any medium or format, provided the original work is properly cited. 


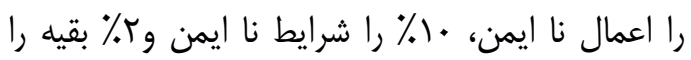
مقدمه - م

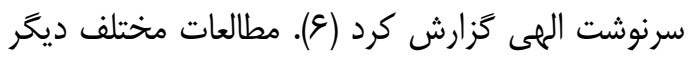
نيز در زمينه حوادث شغلى نشان داد كه عامل انسانى نقش اصلى را در بروز حوادث دارد، به طورى كه آمار

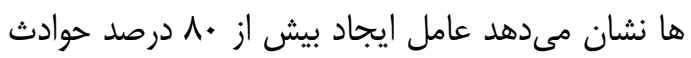
در صنايع شيميايى و وّتروشيمى خطاى انسانى است.به طور كلى، حوادث مهم تاريخى از قبيل ترى مايل آيلند،

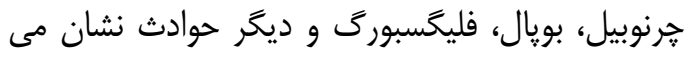

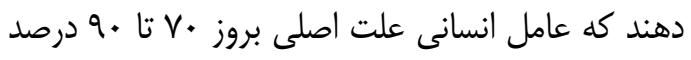

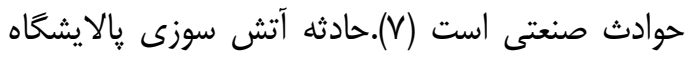
Texaco

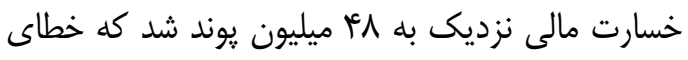

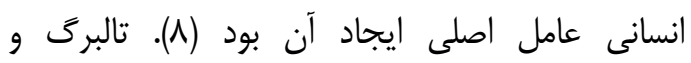
سالمينن معتقدند كه عامل اصلى حوادث شغلى استرالي اليا

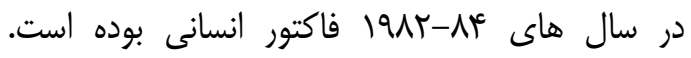
لوتنس نيز تاكيد مى كند كه بيش از هو٪ كل حوادث

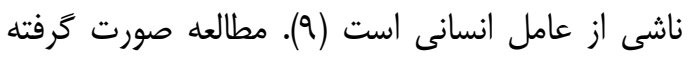
توسط كاكايى و همكاران در يالايشگاه نفت كرمانشاه آناه

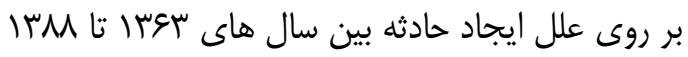

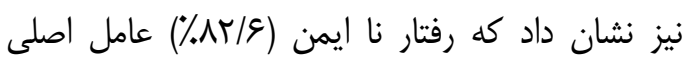

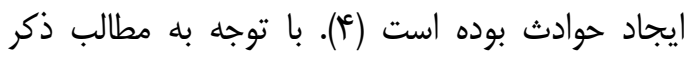
شده در بالا و اهميت اعمال نا ايمن و خطاهاى انسانى در به وقوع ييوستن حوادث و هم هنين نياز به انجام مطالعهاى در اين زمينه براى صنعت مورد نظر، مطالعا

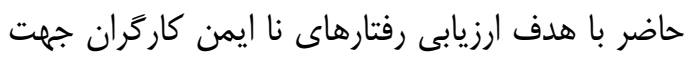

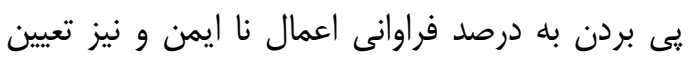

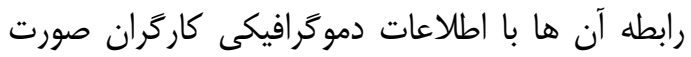

\section{مواد و روش ها:}

مطالعه حاضر به صورت توصيفى - مقطعى، اعمال نا

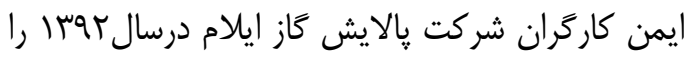
مورد بررسى قرار داد. در اين مطالعه از تكنيك نمونه بردارى از رفتار ايمن (safety behavior sampling)

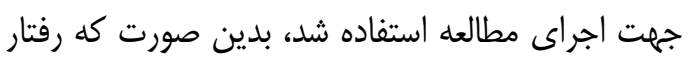
كاركران در حين انجام وظيفه مشاهده شد و با توجه به جى ليست مورد استفاده اطلاعات آنها ثبت شدان

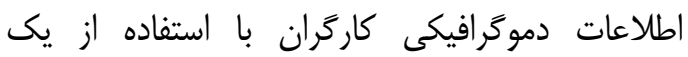
كاز يكى از منابع اصلى مصرف سوخت در جهان است،

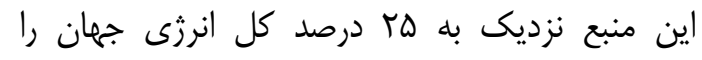

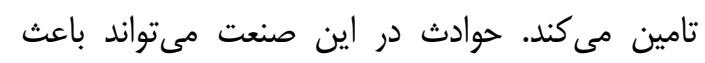

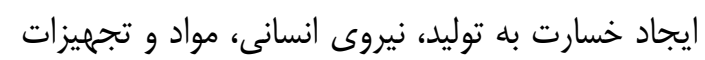
شود و در نتيجه باعث از بين رفتن سرمايه ملى شود. بنا بنا

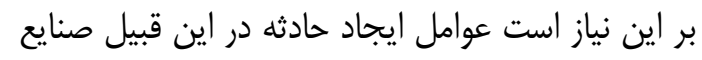

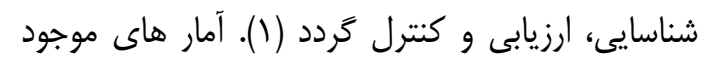

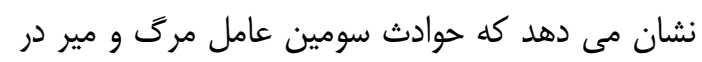

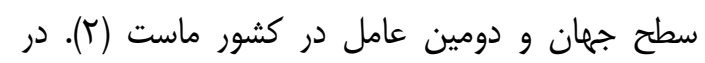

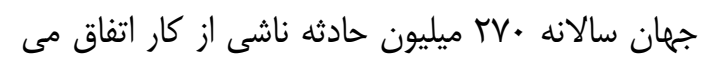

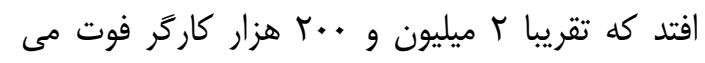

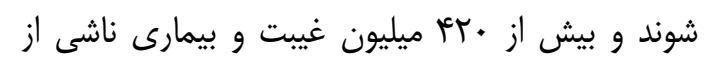

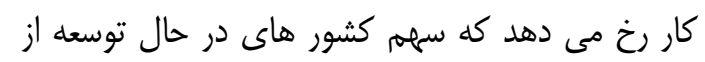
اين ميزان س تأ أ برابر كشور هاى توسعه يافته است. جداى از اين موارد، از نظر مالى نيز برآئ مآورد شده است

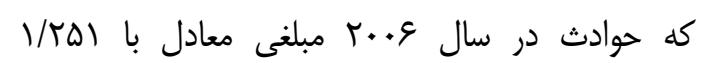

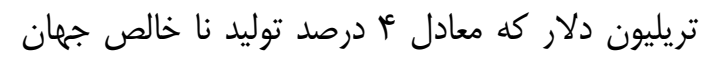

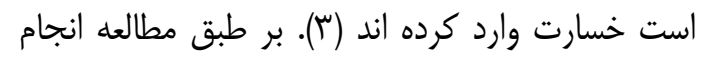

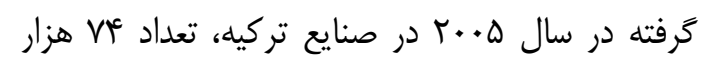

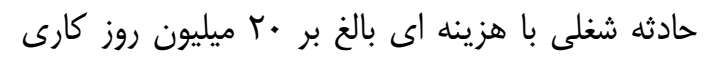

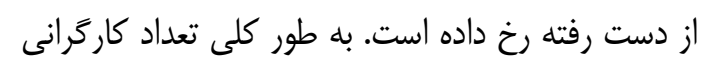

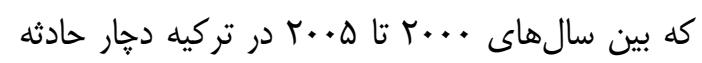

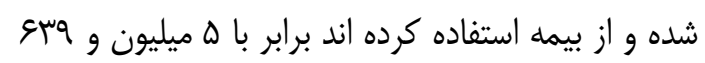
هزار مورد كزارش شده است (أ). با توجه به مطالعات

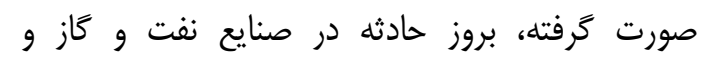

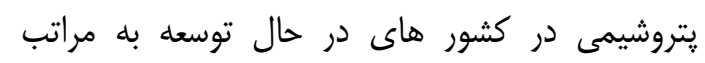

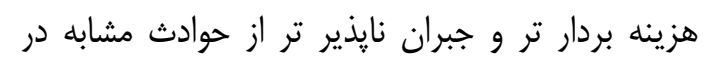

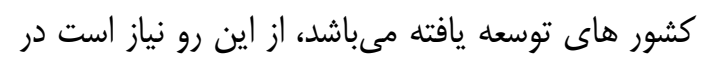

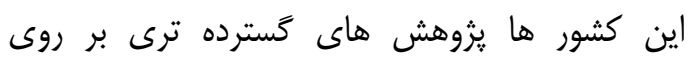
عوامل ايجاد حوادث صورت كيرد (ه). تا قبل از سال

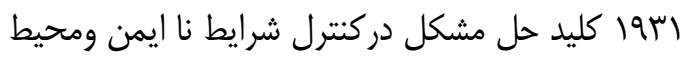
هاى خطر آفرين جستجو مى شد اما تقريبا از نيمه دوم

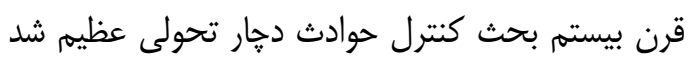

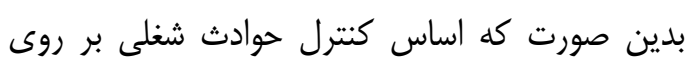

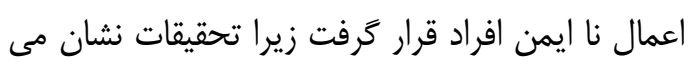

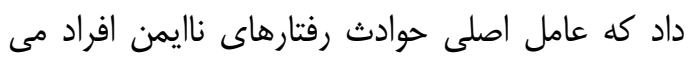

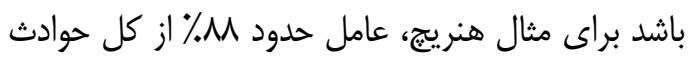


r در نظر گَرفته شد) با جايكزينى درفرمول خواهيم

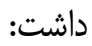

$$
\begin{gathered}
N=\frac{K^{2}(1-P)}{S^{2} P} \\
N=\frac{2^{2}(1-0 / 3)}{(0 / 07)^{2}(0 / 3)}=1878
\end{gathered}
$$

يعنى لازم است حداقل INVA مشاهده براى به دست آوردن نتايج موفقيت آميز صورت كيرد. نمونه گيرى از رفتار بايستى به صورت تصائ صوت كيرد ادفى انجام

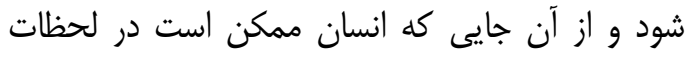

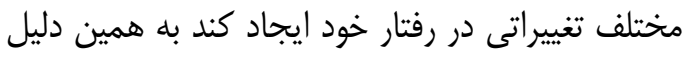

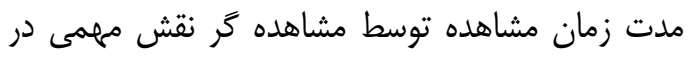

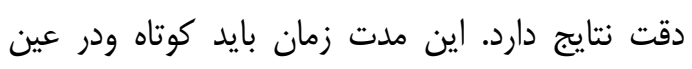

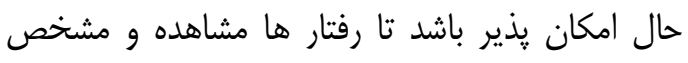

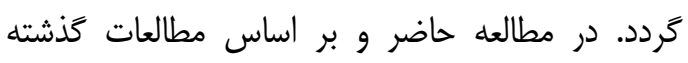

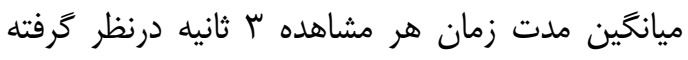

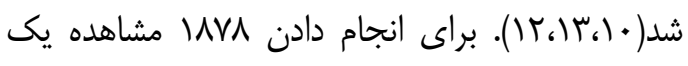

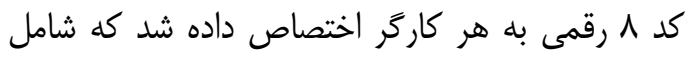
1- سه رقهم اول: كد يرسنلى كاركران r- دو رقم بعدى: روز مشاهده رفت رلتار r- يك رقم بعدى: ساعت مشاهده رفتار ז ك- دو رقم آخر: دقيقه مشاهده رفتار

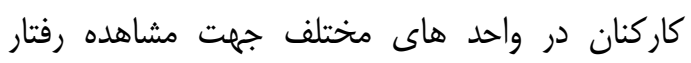

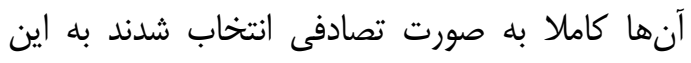

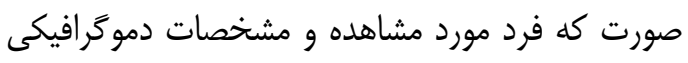

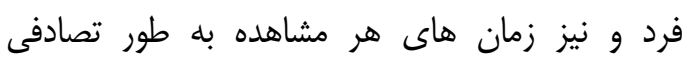

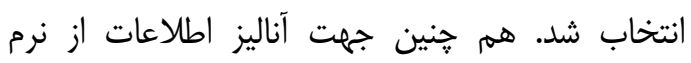
افزار SPSS و آزمون كاى دو استفاده شد.

\section{يافتههاى يزوهث:}

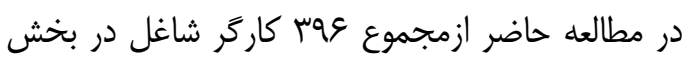

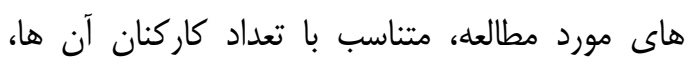

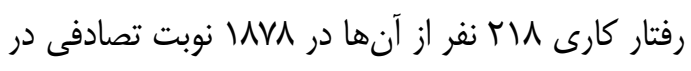

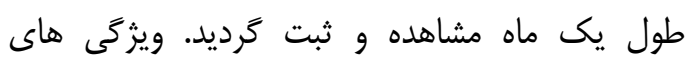

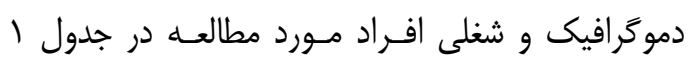

$$
\text { به شرح زير است. }
$$

يرسش نامه كه از قبل توسط محقق آماده شده بود

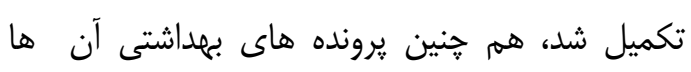
جهت تكميل اطالاعات مربوط به سابقه كار ويا داشتن سابقه حادثه قبلى مورد بررسى قرار كرفت. ازئل

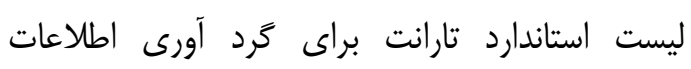

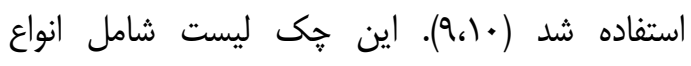

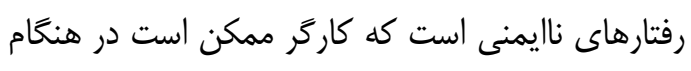

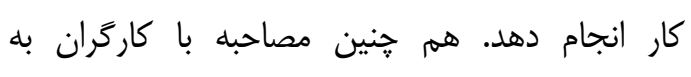

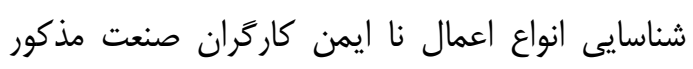

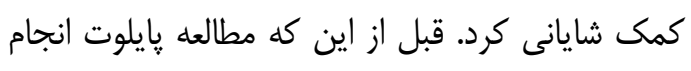

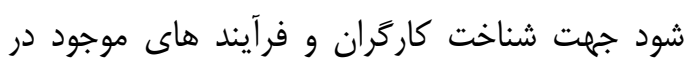

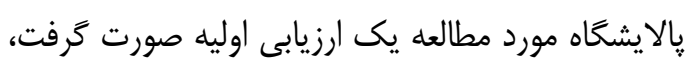

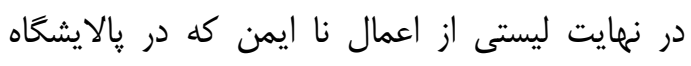

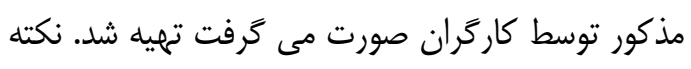
قابل ذكر در انجام مطالعه حاضر اين بود كه كارك كاركران متوجه هدف مشاهده گر در طول مطالعه نشوند زيرا در

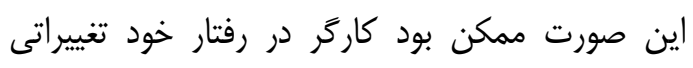
ايجاد كند. قبل از انجام مطالعه يايلوت بائ بايد زمان ران

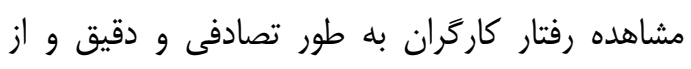
طريق جدول اعداد تصادفى تعيين مىشد. از طريق داده

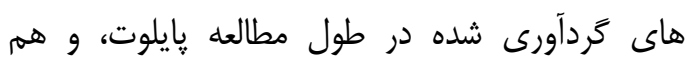
קنين درجه دقت وحدود اطمينان، تعدادكل مشاهدات

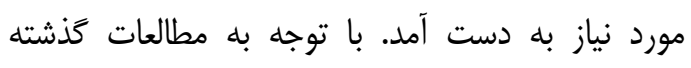

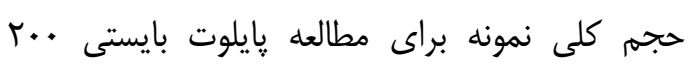

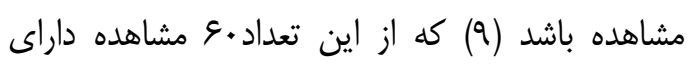
رفتار نا ايمن بودند، بنا بر اين: $P=\frac{\mathrm{N} 2}{\mathrm{~N} 1}$

$$
P=\frac{60}{200}=0.3
$$
(N1)

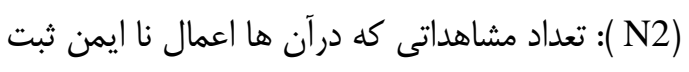
شده است. P در مطالعه حاضر تعداد كل مشاهدات با درجه دقت

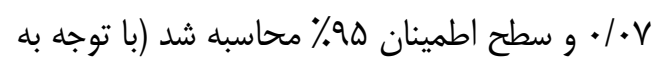

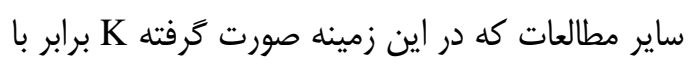


جدول ا: ويزَّى هاى دموكَ افيكى وشغلى افرادمورد مطالعه

\begin{tabular}{|c|c|c|}
\hline بيش ترين (درصد) & كم ترين (درصد) & 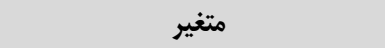 \\
\hline$\Delta f$ & re & سن (سال) \\
\hline تعميرات مكانيك (IV/F) & مستغلات- حمل و نقل (س//؟\%) & تعداد افراد مورد مطالعه در واحدهاى مختلف \\
\hline نوبت كار محوطه (I/T/K) & كارشناس ميكرو بيولوزى(ه.٪٪) & شغل \\
\hline$(\% \cdot g V / F) \mu I-r$. & أf سال و بالا تر (\$/9/\%) & ت توزيع سنى \\
\hline 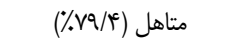 & مجرد (4/.r\%) & وضعيت تاهل \\
\hline 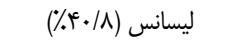 & زير دييلم ("//\%\%) & سطح تحصيلات \\
\hline هاله & عا سال و بالا تر (س/؟r\%) & سابقه كار \\
\hline
\end{tabular}

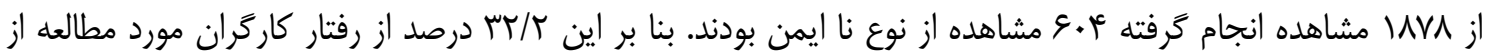

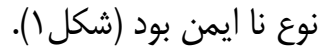

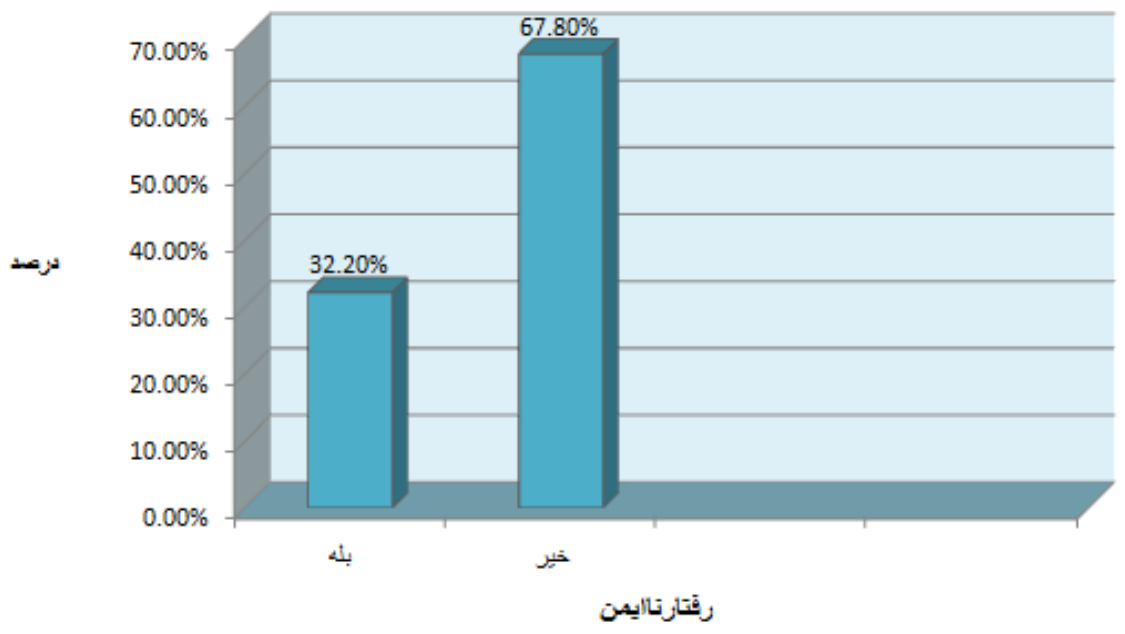

شكل ا: فراوانى نسبى كل رفتارهاى نا ايمن مشاهده شده در پالايشكاه كاز ايلام

مربوط به مقطع فوق ليسانس بود. علاوه بر آن از نظر

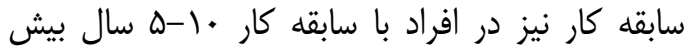
ترين ميزان اعمال نا ايمن و در افر اد با سابقه كار بيشتر

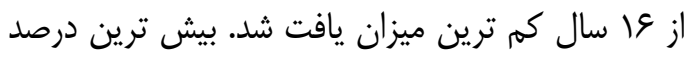

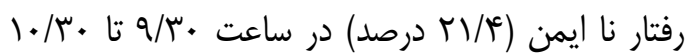

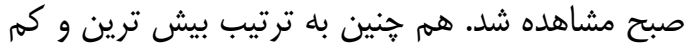

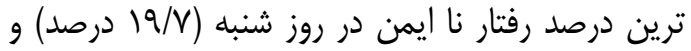

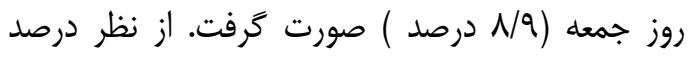

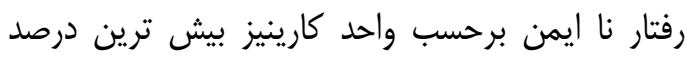

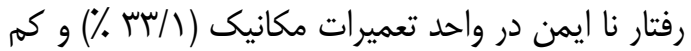

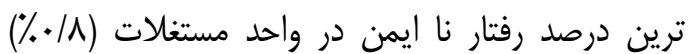
مشاهده شد (جدول r).
بررسى رفتار هاى نا ايمن برحسب متغيرهاى مختلف نشان داد كه به ترتيب بيش ترين ميزان اعمال نا ايمن برحسب شغل مربوط به نوبت كاران محوطه با |F/ |

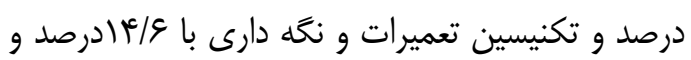
كم ترين ميزان اعمال نا ايمن مربوط به مشاغل نمونه

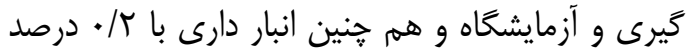
بود. هم هنين نتايج نشان داد كه بيش ترين ميزان

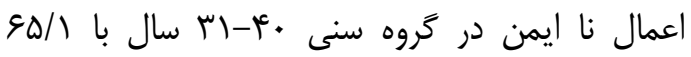
درصد و كم ترين ميزان نيز در گروه سنى الث سال به بالا با أ/سادرصد مشاهده شد. /عم درصد درصد مشاهدات رفتار كارگران متاهل نا ايمن بود.از نظر سطح تحصيلات نيز بيش ترين ميزان اعمال نا ايمن مربوط

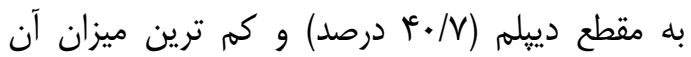


جدول r: ارتباط بين ميزان اعمال نا ايمن با متغير هاى موردمطالعه

\begin{tabular}{|c|c|c|c|}
\hline $\mathrm{p}$-value & بيش ترين ميزان اعمال نا ايمن (درصد) & كم ترين ميزان اعمال نا ايمن (درصد) & 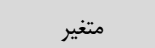 \\
\hline$(<0 / 05)$ & تعميرات مكانيك ( (//سץ\%) & مستغلات (^/•٪) & واحد كارى \\
\hline$(<0 / 05)$ & نوبت كارمحوطه (\&/\& & نمونه گَيرى - انباردارى (T/.\%) & 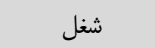 \\
\hline$(>0 / 05)$ & 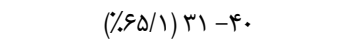 & 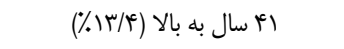 & كروه سنى \\
\hline$(>0 / 05)$ & 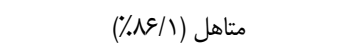 & 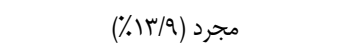 & وضعيت تاهل \\
\hline$(<0 / 05)$ & دييله (V/F\%) & فوق ليسانس (Г٪\%) & سطح تحصيلات \\
\hline$(<0 / 05)$ & $(\% \cdot . \cdot) \Delta-1$. & بيش تر ازع| (V/D/O) & سابقه كار (سال) \\
\hline$(<0 / 05)$ & $(\% / r / / \leftarrow) 1 \cdot / r \cdot-q / r$. & $(\% \Delta / \Delta) \mid r / \mu \cdot-1 r / \mu$. & 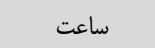 \\
\hline$(<0 / 05)$ & شنبه (19/V) & 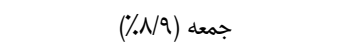 & روز \\
\hline
\end{tabular}

با بررسى يرونده شغلى كاركنان مشخص شد افرادى

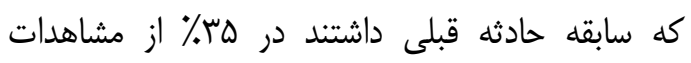

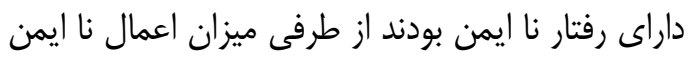

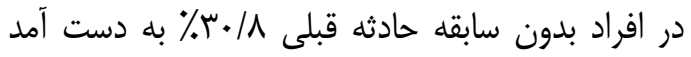

آزمون آمارى كاى دو نشان داد كه بين سابقه كار،سطح

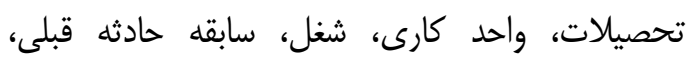

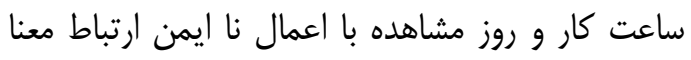

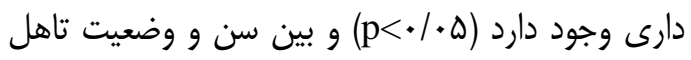

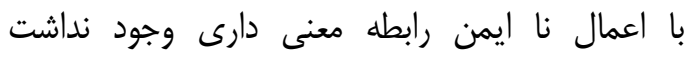

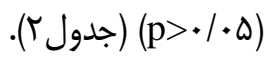

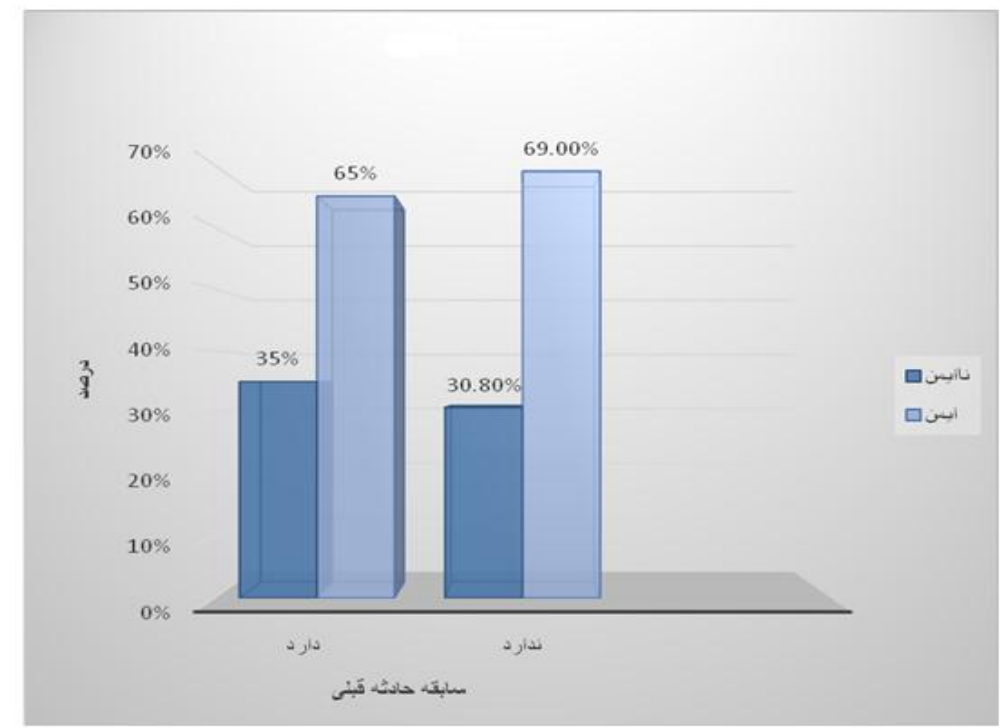

شكل ז: درصد فراوانى نسبى رفتار نا ايمن با سابقه حادثه قبلى در كارتَران مورد مطالعه

ايمن مرتبط با قوانين و مقررات با / /. ٪ درصد (

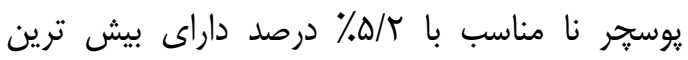

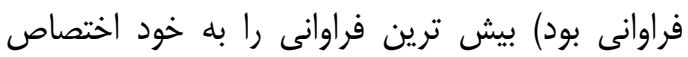

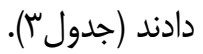

در بين رفتار هاى نا ايمن مشاهده شده در مطالعه

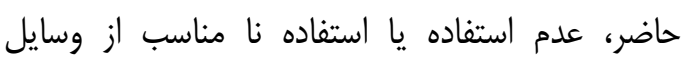

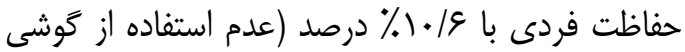
با ه/9 درصد داراى بيش ترين فراوانى بود) و اعمال نا 
جدول س: درصد اعمال نا ايمن برحسب شاخص هاى رفتارى

\begin{tabular}{|c|c|c|c|}
\hline جمع كل مشاهدات & مشاهدات ايمن (درصد) & مشاهدات نايمن (درصد) & شاخصهاى رفتارى \\
\hline$(\%) \cdots) \backslash \wedge \vee \wedge$ & $(\% \wedge 9 / 4) \backslash 9 \vee 9$ & $(\% 1 \cdot 18) 199$ & اعمال مرتبط با وسايل حفاظت فردى \\
\hline$(\%) \cdots) \backslash \wedge \vee \wedge$ & $(\% 9) / 9) \mid V T I$ & $(\% / \mathcal{F}) \backslash \Delta V$ & اعمال مرتبط با عوامل شخصيتى \\
\hline$(\%) \cdots) \backslash \wedge \vee \wedge$ & $(\% \wedge 9 / 9) \backslash 9 M \Lambda$ & $(\% 1 \cdot / 1) 19$. & اعمال مرتبط با قوانين و مقررات \\
\hline$(\%) \cdot \cdots) \wedge \vee \wedge$ & $(\% q \vee / 4) \backslash \wedge r q$ & $(\% / q) p q$ & اعمال مرتبط با ايمنى كار با ابزار \\
\hline$(\%) \cdot \cdots) \backslash \wedge \vee \wedge$ & $(\%$ (\%/I) MArF & $(\% / \% / 9) \Delta F$ & اعمال مرتبط با حمل ونقل \\
\hline$(\%) \cdot \cdots) \wedge \vee \wedge$ & $(\% 9 \Lambda) \backslash \wedge \& \mid$ & $(\%$ \%r & اعمال مرتبط با ايمنى كار با ماشين آلات \\
\hline
\end{tabular}

مطالعه حاضر باشند. از ميان اعمال نا ايمن عمل نا

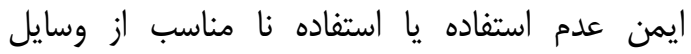
حفاظت فردى و عدم توجه به قوانين و مقررات بيش إنا ترين سهم را به خود اختصاص دادند كه در اين ميان

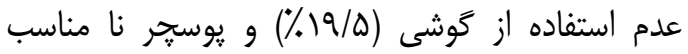

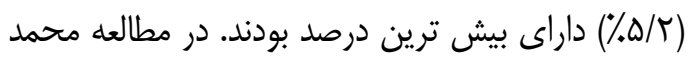

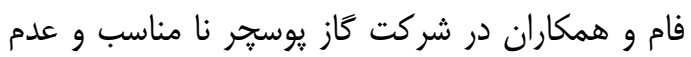
استفاده از وسايل حفاظت فردى بيش ترين درصد رابه

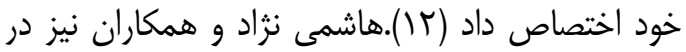

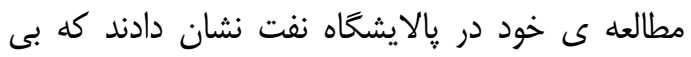

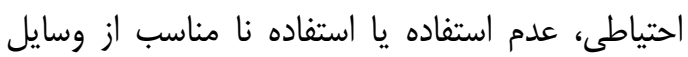
حفاظت فردى و يوسجر نا مناسب بيش ترين رفتار نا ايمن مشاهده شده بود (9). نتايج مطالعه الهيارى و و مطالعه محمد فام در كارخانه ريخته كَى نيز تاييدى

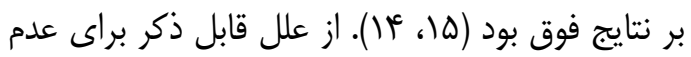
استفاده از وسايل حفاظت فردى ويا استفاده نادرست از

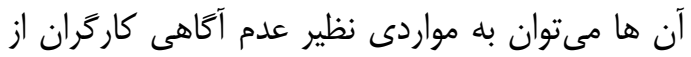

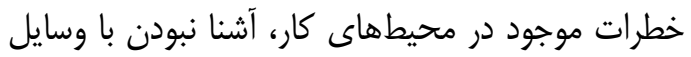

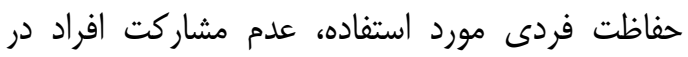
انتخاب وسايل حفاظت فردى ونبود نظارت كافى از سوى مديريت اشاره كرد. هم هنين نتايج نشان داد كه بين متغير هاى سابقه حادثه قبلى، سابقه كار، سطح

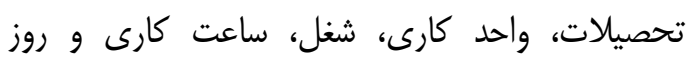
مشاهده با اعمال نا ايمن رابطه معنى دارى وجود داشت

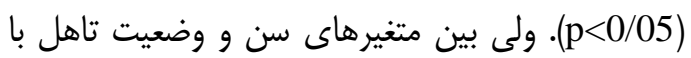

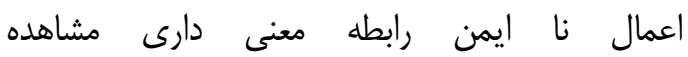
نشد(p>0/05). نتايج مطالعه محمد فام و همكاران در دران كارخانه ريخته ترى و مطالعه هاشمى نزاد و همكاران در يالايشخاه نفت با نتايج مطالعه حاضر هم خوانى

\section{بحث و نتيجه كَيرى:}

مطالعه حاضر در سال זوسا جهت بررسى ميزان اعمال

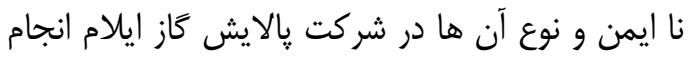

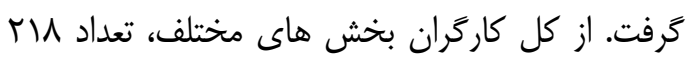
نفر جهت مشاهده رفتار آن ها به صورت تصادفى

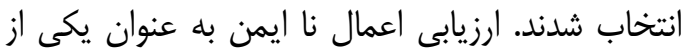

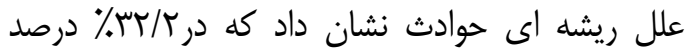

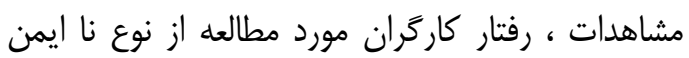

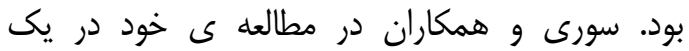
شركت خودرو سازى نشان دادند كه حداكثر شيوع رفتار

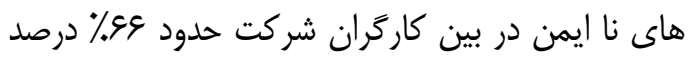

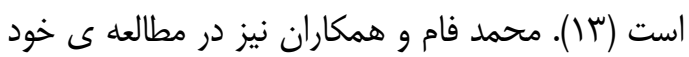

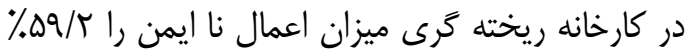
درصد ززارش كردند (أl). در مطالعه ى ديخرى كه توسط محمدفام و همكاران در شركت كاز انجام كرفت

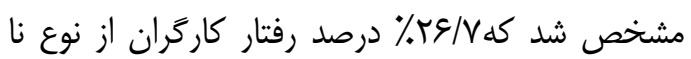
ايمن بود (T). درصد رفتار هاى نا ايمن در مطالعه ى هاشمى نزاد و همكاران در يالايشكاه نفت كرمانشاه

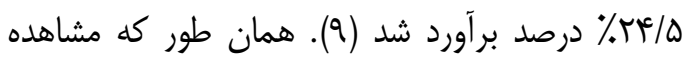
مى شود درصد رفتار نا ايمن در صنايع مشابه با مطالعه حاضر، تقريبا نزديك به نتيجه مطالعه حاضر است و در ساير مطالعات درصد رفتار نا ايمن بسيار بالا تر است.

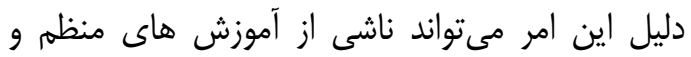

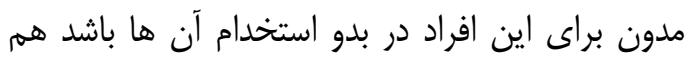
جنين كارگران ممكن است به واسطه آموزش ها و واين قوانين موجود از نتيجه تاثير رفتار نا ايمن خود در اين

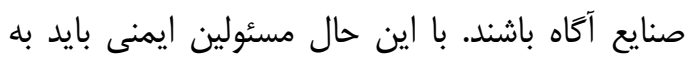

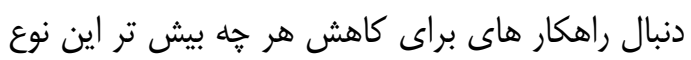
رفتار ها در صنايع مهمه و حياتى از قبيل صنعت مورد 
نتايج نشان داد كه رابطه معنى دارى بين اعمال نا ايمن

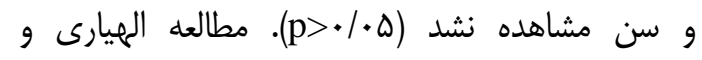

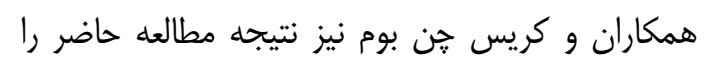

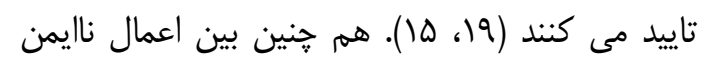
ووضعيت تاهل ارتباط معنى دارى مشاهده نشد. نتايج

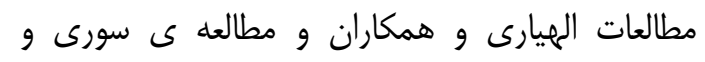
همكاران هم سو بانتيجه مطالعه حاضر بود (ها، سار).

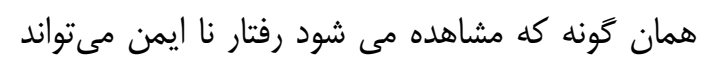

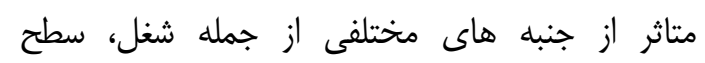

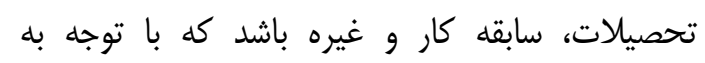

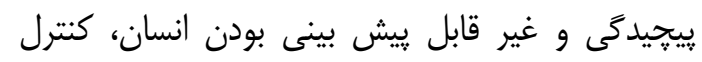

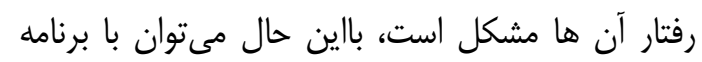
ريزى دقيق و مدون، بسيارى از اين گَونه رفتارها

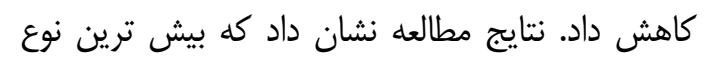

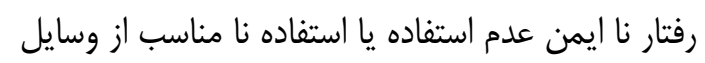
حفاظت فردى و عدم توجه به قوانين و مقررات بود لذا لذا

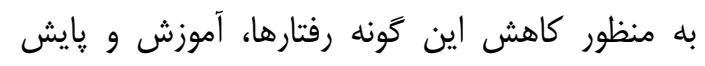

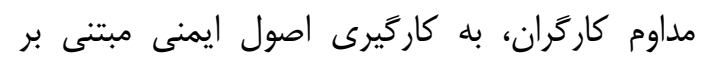

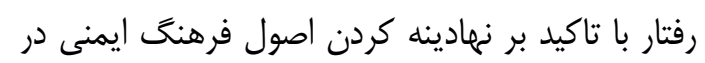
تمام سطوح سازمانى، ايجاد انخيزش و بهببود شرايط كار و محيط كار بيشنهاد مى گردد.

\section{سباسگَزارى:}

اين مقاله حاصل انجـام طـرح تحقيقـاتى مصـوب

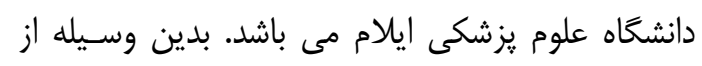

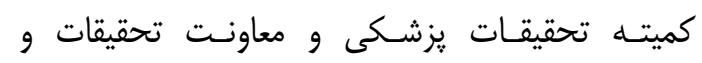

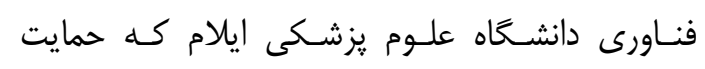

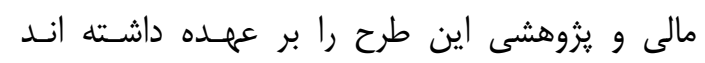

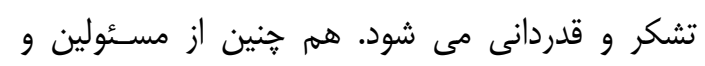

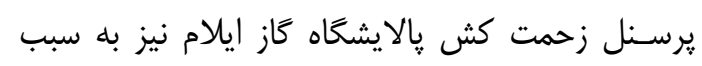
همكارى صميمانه در انجام اين طرح تشكر و قدر قدردانى

$$
\text { مى شود. }
$$

\section{References:}

1.Ghasemi S, Yavari K, Mahmmodvand R, Sahabi B, Naeimi A R. [Offering a new way to assess insurability risks in gas refinery using FMEA method]. J Econ Po 2015;7:26.(Persian)
داشت (fأ، 9). در ارتباط با معنى دارى رابطه بين

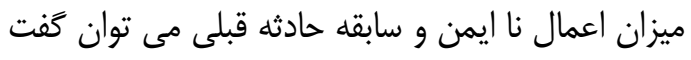

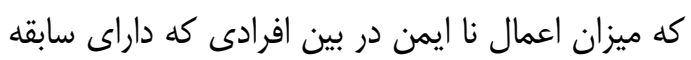
حادثه قبلى بودند بيش تر از افراد بدون سابقه حادئ دادثه

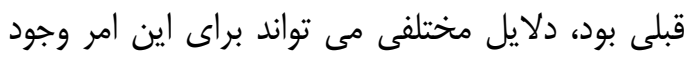

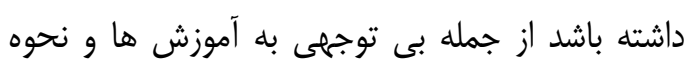

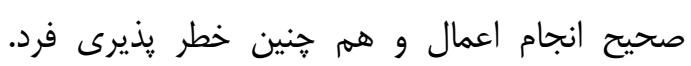

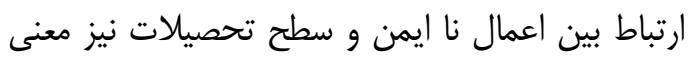

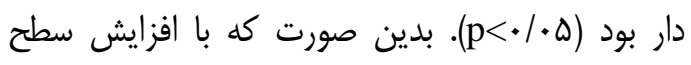
تحصيلات ميزان اعمال نا ايمن كاهش يافت. نتايج

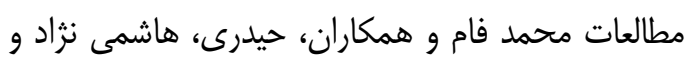

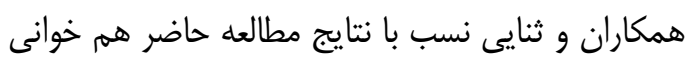

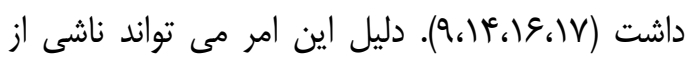

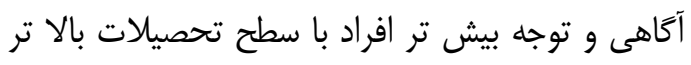

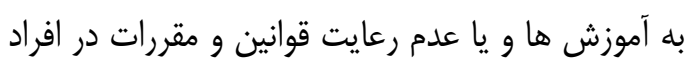
با سطح تحصيلات يايين تر و نيز فعاليت بيش تر اين

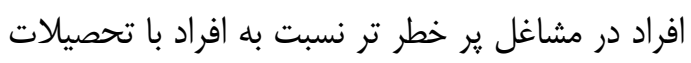

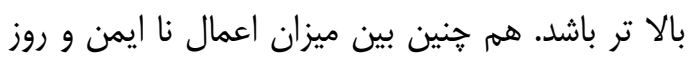

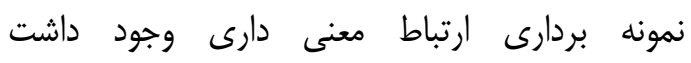

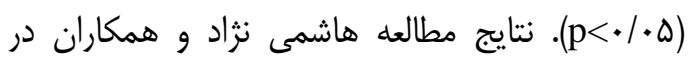

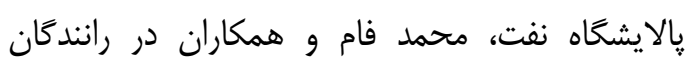
اتوبوس هاى بين شهرى و حيدرى در شركت يترو

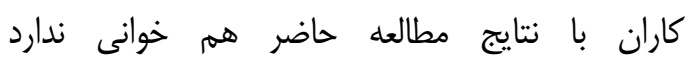

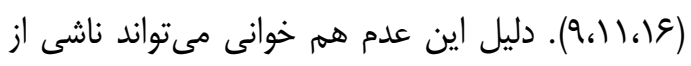
تعداد روز هاى مورد بررسى و نيز توزيع نسبت تعداد

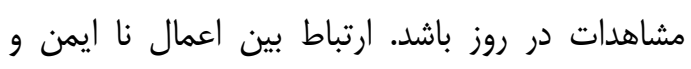

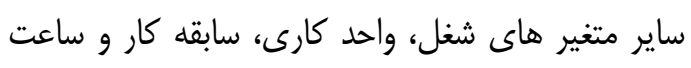

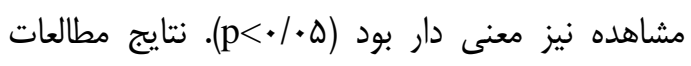

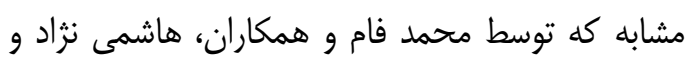

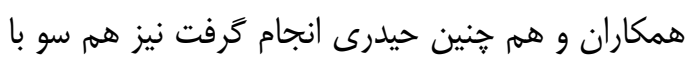
نتايج مطالعه حاضر بود (1)، (9)،وج).

2.Mohammadfam I. [Application of safety signs in controling unsafe acts rate]. Iranian J Military Med2010;12: 39-44. (Persian)

3.Mansouri N, Hosaini Sh. [HSE performance ratings for gas companies using multiple attribute decision making 
technique]. Environ Sci Technol2015;17:920. (Persian)

4.Kakaei H, Hasheminejad N, Mohammadfam I, Shokouhi M, Ahmadi M, Kakaei H, et al. [Reasons of occupational accidents in Kermanshah petroleum refinery a retrospective study 1984-2009]. J Ilam Uni Med Sci 2012; 20: 44-52. (Persian)

5.Amini A. Safety and risk management in the petrochemical industry.First National Confer Safe Engin HSE Manage2005;232.

6.Seo DC. An explicative model of unsafe work behavior. Safe Sci2005; 43:187-211.

7.Ghasemi M , Nasl Saraji G, Zakerian A, Azhdari M R. [Control of human errors and comparison of risk levels after correction action with the SHERPA method in a control room of petrochemical]. Iran Occup Health 2011;8:14-22. (Persian)

8.Zarrnezhad A, Jabbari M, Keshavarzi M. [Identification of the human errors in control room operators by application of HEIST method case study in an oil company]. Iran Occup Health 2013; 10: 1123. (Persian)

9.Hashemeinejad N, Mohammad Fam I, Jafari R, Dortaj E, Kakaei H, Kakaei H. [Assessment of unsafe behavior types by safety behavior sampling method in oil refinery workes in 2009 and suggestions for control]. Occup Med quart J 2012;4:25-33. (Persian)

10.Tarrants WE. Accident counsel factors obtained from the critical incident study in the measurement of safety performance garland. STPM New York Publication. 1980; P.414.

11.Mohammadfam I, Golmohammadi R. [Evaluation of safety behavior among coach driversin Hamadan] J Hamadan Uni Med Sci 2003;5:60-251. (Persian)
12.Mohamadfam I, Nouri J, Azadeh A. [The evaluation of safety behaviors in a gas treatment company in Iran]. J Loss Preve Proce Indus 2008;21:25-319. (Persian)

13.Soori H, Mortazavi M, Shahesmaeil A, Mohseni H, Zagiabadi M, Ainy E. [Determination of workers risky behaviours associated with safety and health in a car manufacturing company in 2011]. Arak Uni Med Sci J 2013;16:52-61. (Persian)

14.Mohammadfam I, Zamanparvar A. [Unsafe acts among melt casting factory worker in Hamedan].J Hamadan Uni Med Sci 2002;9:6-51. (Persian)

15.Allahyari T, Adle J. [Evaluation safety system performance a manufacturer of industrial by safety sampling method]. Tehran Uni Med Sci J2000;2:32-8. (Persian)

16.Heidari M. Survey the role of human errors in the incidence of work accidents and the effect of education participation and monitoring the behavior workers the incidence and severity of events in Petrokaran company. Fourth National Confer Occup Health Iran Hamadan 2004;639-46.

17.SanaeiNasab H, Ghofranipour F, Kazemnejad A, etal. Evaluation of knowledge, attitude and behavior of workers towards occupational health and safety. Iranian J Publ Health 2009;38:1259.

18.Mohammadfam I, Ashtari M, Ziaee M, etal. Unsafe behavior among employees of Mobarakeh steel company Isfahan. First Con Indusl Saf Sta Health Profe Environ Organ Isfahan 2007.

19.Kirschenbaum A, Oigenblick L, Goldberg A. Wellbeing work environment and work accidents. Soc Sci Med 2000;50:631-9. 


\title{
Identifying unsafe Behaviors with Safety Behavior Sampling Method among Workers of Ilam Gas Refinery in 2013
}

\author{
Garavand $Z^{1}$, Kakaei $H^{2 *}$, Mirzai $F^{3}$, Jamshidzadeh $C^{3}$, Zeydimofrad $M^{3}$, Garavand $U^{4}$, Poornajaf $A^{3}$
}

(Received: July 20, 2015

Accepted: July 13, 2016)

\begin{abstract}
Introduction: Gas Refinery is one of the strategic industries in the country and the events happening there can cause irreparable damage, therefore it is very important to control events and identify its causes. This study conducted also aims to identify the types of unsafe behavior that is one of the causes of accidents in refineries.
\end{abstract}

Materials \& methods: In this cross-sectional study using the safety sampling technique and enjoying observation method and Tarrant checklist, unsafe act of workers were studied. To complete demographic profile of workers, they were interviewed. To determine the amount and types of unsafe behavior with a pilot study sample size, the view was set in 1878. For data analysis, SPSS software and chi-square test were used.

Findings: The results showed that $32.2 \%$ of workers' behaviors are unsafe. The highest unsafe behavior and its types in Mechanical Repair (33/1\%) and non-use or inappropriate use of personal protective equipment $(10 / 6 \%)$ were observed, respectively. Also, relationship between unsafe acts of workers with the unit, job, education level, work experience, previous accident history, hours and days were statistically significant ( $\mathrm{p}<0 / 05)$, but relationship between unsafe acts with age and marital status were not significant ( $\mathrm{p}>$ $0 / 05)$.

Discussion \& conclusions: Given that most unsafe behavior was in mechanical maintenance unit and the most types it was inappropriate use of personal protective equipment, to reduce these behaviors, continuous monitoring of workers, training courses on the principles of behavior-based safety, creating a safety culture and safety climate and use of scientific expertise of university researchers were recommended.

Keywords: Unsafe behavior, Behavior sampling, Gas refinery, Ilam

1. Student Research Committee, Ilam University of Medical Science, Ilam, Iran

2.Dept of Occupational Health, Faculty of Public Health, Tehran University of Medical Sciences, Tehran, Iran

3. Dept of Occupational Health, Faculty of Public Health, Ilam University of Medical Sciences, Ilam, Iran

4. Dept of Business Management, Faculty of Management, University of Payamnoor Tehran, Tehran, Iran

*Corresponding author Email:hojatkakaei@gmail.com 